\title{
Trust and Discourse: Organizational Perspective Edited by Katja Pelsmaekers, Geert Jacobs, and Craig Rollo
}

\section{Reviewed by Xueyu Wang}

Trust and Discourse: Organizational Perspective is a part of Benjamins' DAPSAC (Discourse Approaches to Political, Society and Culture) series, which investigates political, social, and cultural interaction from a linguistic/discourse-analytic point of view. Exploring the relations of trust and discourse in various organisational settings by means of "broadly pragmatic approaches that are relevant for the phenomena observed" (p. 8), this collection of papers intends to shed light on new perspectives for studying trust and organisational discourse.

This book features ten chapters. In Chapter 1 ('Trust and Discursive Interaction in Organizational Settings'), Pelsmaekers, Jacobs, and Rollo provide a theoretical background by reviewing some selected theories of trust. Special attention is paid to Garfinkel's conception of trust as "a normal and necessary condition that informs any participants' entry into any given interaction for it to make sense" (p. 5). However, as these authors wisely put it, the links between trust and language are not that simplified but manifold; trust shapes, and conversely is shaped by, "the nitty-gritty of interpersonal communication" (p. 6). They also point out that organisational interaction underlies the interesting process of trust negoti-

\section{Affiliation}

Nantong University, China

email:wangxueyu2012@gmail.com 
ation between the in-groupers and the outsiders, thus providing good data for analysing the largely discursive nature of "doing" trust.

In Chapter 2 ('Trust in Action: Building Trust through Embodied Negotiation of Mutual Understanding in Job Interviews'), Kuśmierczyk focuses on the particular aspects of trust relating to the construction of mutual understanding and presentation of believable identity in the job interview environment. Adopting a method of multi-modal (inter)action analysis, she explores how trust is established through a range of intertwined multimodally constructed features like gesture, gaze, and written text, as well as speech. A methodological contribution of this chapter is that the author takes an emic approach in trust judgment, relying on the interviewers' comments to judge the credibility of the interviewees' discursive practices.

Chapter 3 ('The Reciprocal Nature of Trust in Bedside Teaching Encounters') presents a qualitative analysis of "doing" trust in the triadic interaction between doctor-patient-student(s) throughout bedside teaching encounters (BTEs). Adopting a video ethnographic approach, Elsey, Monrouxe, and Grant explore how trust is interactionally realised across various phases of interaction - openings, history-taking, and closings - in medical settings. The setting-specific features of trust negotiation within BTEs are also highlighted in this chapter.

Chapter 4 ('They Just Want to Confuse You: Negotiating Trust and Distrust in Adult Basic Education') is about (dis)trust negotiation in educational encounters. In this chapter, Oughton examines the audio-recordings of adult numeracy students' naturally occurring classroom discussions under the theoretical framework of Halliday's systematic functional analysis. The investigation reveals a contrast between students' trust in classroom teachers and their mistrust of pedagogic texts. An attractive part of this chapter lies in the analysis of the participants' use of the pronoun they as a marginalisation marker to "express a distrust of authority" (p. 89). The findings of this study are expected to yield valuable insights into both classroom instruction and curriculum assessment in the field of adult education.

Chapter 5 ('In Foreign News we Trust: Balance and Accuracy in Newspaper Coverage of Belgium') reports an investigation of trust from trustee's perspective in news media setting. Through an analysis of a corpus of 48 foreign news articles and interviews with some journalists, this chapter explores how foreign correspondents engage with their domestic readers while at the same time trying to negotiate a trust relationship with them. The results indicate that, besides trust, some other notions like entertainment or information compensation are at play in correspondents' attempts to engage with their domestic readers. The authors conclude this chapter by echoing Peterson's (2003) view that journalism is "a complex web of signification involving not only technical skills and knowledge, 
but ethics, aesthetics and audience". The detailed investigation of choice-making at various levels could give valuable suggestions for improving news delivery.

In Chapter 6 ('Trust Work: A Strategy for Building Organization-Stakeholder Trust?'), Jackson presents a case study of an Australian enterprise, focusing on the development of relational trust between managers and employees after the implementation of a Trust Strategy (TS). Adopting a discourse-oriented ethnographic approach, the author shows that managers and employees orientated themselves to the TS differently, revealing tensions in their relationships which were caused by employees' trusting their managers' personality rather than trusting their managerial ability. I concur with the author that the finding of this study "provides empirical evidence in support of a two-dimensional definition of relational trust" (p. 114).

Chapter 7 ('Put Yourself Down to Build Trust: The Effect of Self-Disparaging Humor on Speaker Ethos in Educational Presentations') focuses on the effect of self-disparaging humour on instructors' ethos in educational presentations shown to university students. Based on the analysis of two systematic experiments in an educational setting, this chapter attempts to dig deep into the relation between self-disparaging humour as a 'presentation style' and the concept of a speaker's trustworthiness in public speaking. The results of both experiments show that the use of self-disparaging remarks in presentations has no benefit for a speaker hoping to leave a credible impression on the audience. Personally, I like this chapter the best because it relies on empirical data rather intuitive observations to examine the effectiveness of the highly recommended rhetorical tool in lectures and presentations.

Temmerman in Chapter 8 ('Trust Us: Bootcamp Pilates Does not Sound Half as Hard as it is but it Works. The Credibility of Women's Magazines'), conducts a text-based linguistic discourse analysis of a Belgian Dutch-language women's magazine, focusing on its use of a wide range of discursive tools to communicate trustworthiness to its readers. The finding shows that women's magazines usually adopt an expert position for communicating trustworthiness, realised in the strategical deployment of imperatives, pseudo-dialogue, and the first person plural pronoun we. The fine-grained analysis of the data in this chapter is quite impressive.

A historical perspective is adopted in the last two chapters. Chapter 9 ('There is Reason to Believe, However ... The Construction of Trust in Late Modern English Correspondence and Non-literary Prose') explores the verbal means of developing trust relationships in nineteenth-century business letters and non-literary prose. Underpinned by the tenets of historical pragmatics, historical sociolinguistics, and corpus-based discourse analysis, this chapter describes rich linguistic resources at the levels of lexis, syntax, and pragmatics for trust construction in 
the data. For example, the use of open-class lexical items (nouns, verbs, adjectives, and adverbs) and instances of epistemic and deontic modality, as well as politeness moves - and particularly, repeated expressions of trust in many forms - contribute to the manifestation of trust in these historical data.

Finally, in Chapter 10 ('Discursive Construction and Deconstruction of Trust: The Aftermath of a Nuclear Accident'), Tanaka and Kawamata investigate the dynamic change of Japanese public trust in the government before and in the aftermath of a nuclear accident in Tokaimura, Japan in 1999. Working multi-methodologically by incorporating a discourse-historical approach, corpus-based microlinguistic analysis, and ethnography, the authors present evidence to show that initially the Japanese modern assumption created a strong public trust, but later the public's resistance to the fixed power relation transformed their prior trust into interrogation, thus demonstrating the dynamism within modernity which affects public trust.

Taken as a whole, Trust and Discourse: Organizational Perspective constitutes a valuable contribution to the existing literature on trust analysis and professional discourse analysis. The ten chapters in the volume investigate trust construction in various professional fields, ranging from private businesses to public organisations like education, medical care, and government. All the data analysed are real languages in "a wide geographical and cultural spread" (p. 8), consisting of both written and spoken data from the UK, Belgium, the Netherlands, Japan, Australia, and New Zealand.

A particular attraction of the volume lies in the various kinds of research methods adopted (including multimodal analysis, corpus-based linguistic analysis, a social-historical approach, and ethnography) and a variety of empirical data selected (including texts, conversational excerpts, ethnographic data, publicised documents, and historical background information) to dig deep into the phenomenon of trust. In addition, the firm empirical basis of all studies and the inclusion of a historical perspective in trust analysis (in last two chapters) are also strong points of the book. Finally, all the chapters describe the theoretical background in great detail and analyse the selected examples or excerpts in elaborated ways. As such, the readers can easily appreciate the book without relying on much background knowledge in the fields of linguistics or organisational discourse analysis.

Overall, this volume undoubtedly provides valuable insight into trust studies, discourse analysis, as well as pragmatic research, and thus is highly recommended to scholars in these fields.

\section{Reference}

Peterson, M. A. (2003). Anthropology and mass communication: Media and myth in the new millenium. New York: Berghahan Books. 